Original Research Paper

\title{
Pest and Disease Identification in Parijoto Plant (Medinilla speciosa blume) at Nglurah Tawangmangu
}

\author{
Weli Umiyati ${ }^{1 *}$, Manda Ayu Pramesti ${ }^{1}$, Elin Pujiastutik ${ }^{1}$ \\ ${ }^{1}$ Program Studi Pendidikan Biologi, Universitas Veteran Bangun Nusantara Sukoharjo, Indonesia
}

\author{
Article History \\ Received : September $18^{\text {th }}, 2021$ \\ Revised : October $27^{\text {th }}, 2021$ \\ Accepted : November $03^{\text {th }}, 2021$ \\ Published : November $13^{\text {th }}, 2021$ \\ *Corresponding Author: \\ Weli Umiyati, \\ Universitas Veteran Bangun \\ Sukoharjo,Indonesia; \\ Email:weliumiyati99@yahoo.com
}

\begin{abstract}
Parijoto (Medinilla speciosa blume) is a tropical plant that has purplish pink fruit often called Asian grape. In Indonesia, parijoto plants are very well known as ornamental plants that have various benefits, from parijoto fruit can be used as anti-inflammatory drugs so that ornamental plants are widely cultivated by the community, especially lovers of ornamental plants and ornamental plant cultivation in Nglurah. Medinilla speciosa blume is very suitable in Indonesia, which has a tropical climate, but the high rainfall in Indonesia in the rainy season should get more attention in caring for it. This makes parijoto plants susceptible to several types of diseases and pests that can damage the beauty of the Medinilla speciosa blume plant. However, the lack of experts in this field makes it very difficult for plant lovers and the cultivation community of Medinilla speciosa blume in Nglurah to solve the problem of diseases and pests that attack the Medinilla speciosa blume plant. The purpose of this study was to determine pests and diseases on Medinilla speciosa blume. This research was conducted in Nglurah Village Rt 01 Rw 02 Tawangmangu for five days on 04 - 08 September 2021. This research uses observation and interview methods. Data were analyzed by qualitative descriptive. This study used 10 samples of the observed Medinilla speciosa blume plant. The tools used are cellphone cameras and stationery. The variables to be observed are pests and diseases. The results of this study found 4 pests and 2 diseases on Medinilla speciosa blume including Fussarium oxysporum, Cercospora sp and Pestalotia sp, mealybugs, caterpillars, snails, grasshoppers. For this reason, the solution for treating parijoto plants to avoid pests and diseases requires extra care such as paying attention to soil moisture, giving appropriate fertilizers, and giving vitamins so that parijoto plants can grow well.
\end{abstract}

Keywords : Parijoto Plant, Disease, Pest, Qualitative Descriptive

\section{Pendahuluan}

Tanaman Parijoto (Medinilla speciosa blume) tersebar di Indonesia terutama di pulau Jawa dan merupakan jenis tanaman hutan tropis (Widjanarko, 2013). Tanaman parijoto tumbuh secara liar, tetapi tanaman ini juga dapat dibudidayakan di pekarangan, pot, maupun sebagai tanaman hias (Elfrida, 2015). Tanaman parijoto atau sering disebut anggur Asia yang mempunyai keunikan dan berbagai manfaat terutama di bidang kesehatan. Salah satu keunikan dari tanaman parijoto yaitu buah berbentuk bulat secara bergerombol yang berwarna merah muda keunguan dan daun yang berwarna hijau dengan tekstur lembut seperti kulit (Rimba kita, 2019). Hal ini membuat daya tarik sendiri bagi pecinta tanaman hias. Selain itu, tanaman parijoto bermanfaat bagi kesehatan diantaranya daun dan buah parijoto terasa masam, pahit, dan bersifat menyegarkan karena buah parijoto mengandung saponin, kardenolin, dan flavonoid, sedangkan daunnya mengandung saponin, kardenolin, dan tanin (Zuhud et al., 2014). Semua kandungan yang ada didalamnya baik untuk membantu pembentukan otak janin. Kemudian dalam penelitian melaporkan bahwa ekstra metanol buah Parijoto mempunyai kandungan antioksidan yang cukup tinggi. Berdasarkan penelitian yang dilakukan terhadap tanaman yang berpotensi sebagai afrodisiaka, adanya kandungan flavonoid yang berkhasiat sebagai antioksidan mampu 
mempertahankan motilitas sperma (Musfirah et al, 2016). Daun dan buah parijoto tersebut baik dalam kondisi segar maupun dalam bentuk yang sudah dikeringkan dapat digunakan untuk mengatasi sariawan, diare, dan radang (Kementrian Negara Riset dan Teknologi, 2015). Dari kelebihan tersebut tidak heran jika tanaman parijoto banyak dibudidayakan oleh masyarakat dan digemari para pencinta tanaman hias karena dilihat dari berbagai keunikan dan manfaat dari tanaman parijoto.

Tanaman parijoto merupakan tanaman khas dari Desa Colo-Kudus, Jawa Tengah. Desa Colo ini terletak dilereng bukit Muria, yakni salah satu bukit di Gunung Muria yang memiliki tinggi lebih dari 1600 meter. Tanaman Parijoto (Medinilla speciosa Blume) biasanya tumbuh di hutan dan lerenglereng gunung, namun sekarang Tanaman Parijoto (Medinilla speciosa Blume) sudah mulai dibudidayakan sebagai tanaman hias karena warna buahnya yang mencolok. Tanaman ini bahkan disebut sebagai tanaman primadona karena keelokan rupanya (Widi, 2014).

Berdasarkan dari uraian diatas dapat disimpulkan bahwa tanaman parijoto memiliki kandungan kimia yang sangat bermanfaat dan keunikan dari buah parijoto yang mencolok menjadi suatu daya tarik para pecinta tanaman hias. Selain itu, tanaman parijoto juga dapat dimanfaatkan dalam pembuatan motif batik (Fatma, 2019). Jenis tanaman parijoto mempunyai 2 varietas yaitu parijoto lokal dan Thailand.

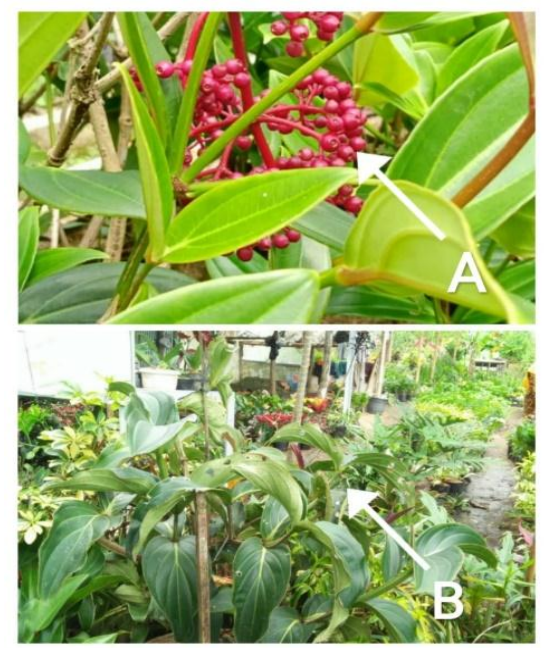

Gambar 1.1 A) Jenis parijoto Lokal; B) Jenis tanaman parijoto Thailand (Dokumentasi Pribadi)
Penanaman tanaman parijoto menggunakan 2 cara yaitu secara stek dan disemai. Tanaman parijoto yang ditemukan di lapangan menggunakan cara disemai dari biji buah parijoto. Benih parijoto yang sudah disemai ditempatkan di media tumbuh campuran pupuk kandang atau kompos halus dan tanah berbanding 1:1 dengan ketebalan media semai $\pm 3 \mathrm{~cm}$. tempat persemaian menggunakan polybag, kotak kayu atau kotak plastik. Kemudian benih disebar secara merata pada media tumbuh yang sudah dibasahi secukupnya dan ditutup dengan tanah halus setebal $\pm 1 \mathrm{~cm}$. Tiap lubang media tanam diisi 1-2 biji parijoto. Penyiraman tanaman ini dilakukan setiap hari (Jurustani, 2019). Bibit benih parijoto yang sudah tumbuh daun 4 atau lebih menunjukkan tanaman parijoto sudah siap dipindahkan ke dalam wadah berupa pot, polybag, kotak kayu atau kotak plastik. Untuk proses penanaman di media pot diperlukan media tanah, kompos, sekam dengan perbandingan 2:1:1 yang sudah disiram dengan campuran pupuk organik padat 1 sendok makan pupuk organik padat untuk 2 liter air. (Jurustani, 2019).

Perawatan tanaman parijoto untuk menghasilkan tanaman yang baik perlu perawatan ekstra agar menghasilkan buah yang indah. Namun tingginya curah hujan di Indonesia pada musim penghujan harus mendapatkan perhatian lebih dalam merawatnya. Tanaman Parijoto tidak jauh dari berbagai serangan penyakit maupun hama. Hal ini membuat tanaman parijoto diserang berbagai jenis penyakit dan juga hama yang dapat merusak keindahan tanaman Medinilla speciosa blume. Namun kurangnya ahli dibidang tanaman ini membuat pecinta tanaman hias dan masyarakat budidaya Medinilla speciosa blume di Nglurah sangat sulit dalam memecahkan masalah tentang penyakit dan hama yang menyerang tanaman Medinilla speciosa blume (Muttaqin, 2021).

Kendala dalam perawatan tanaman diatas juga dapat mempengaruhi kendala dalam proses perdagangan seperti jumlah peminat tanaman parijoto berkurang yang disebabkan kerusakan tanaman saat masa penjualan, misalnya kerusakan sedikit saja ada sobekan pada daun dapat mempengaruhi daya jual dimasyarakat dan pada saat intensitas hujan tinggi maka dalam proses perdagangan/pemasaran Medinilla speciosa blume juga akan terhambat. Selain itu, kendala dalam perawatan tanaman parijoto seperti mudah terserang hama dan penyakit, pada musim hujan 
tinggi tanaman parijoto akan mudah busuk dan cepat menguning dan sehingga pada waktu musim hujan memerlukan perawatan yang ekstra mulai dari pemberian air, mengukur kelembaban tanah, pemberian pupuk dan vitamin agar tanaman parijoto tidak mudah terserang hama dan penyakit (Muttaqin, 2021).

Permasalahan dalam usaha produksi tanaman hias disebabkan oleh hama sehingga perlu adanya penanganan untuk mengendalikan serangan hama secara dini karena hama banyak merugikan tanaman hias sehingga penghasilan usaha produksi tanaman hias menurun (Suhada, 2014).

Hama yang sering menyerang berbagai macam jenis tanaman, terutamanya tanaman buah, hias, sayuran ataupun tanaman lain salah satunya adalah Kutu putih atau dikenal Kutu kebul. Hama ini akan menyerang pada batang tangkai daun, batang tanaman, buah dan daun misalnya penyakit busuk batang (Fitri 2019). Hama yang menyerang pada tanaman parijoto seperti kutu putih, belalang, bekicot, ulat, dan perubahan lingkungan membuat beberapa hama dapat menjadi predator bagi tanaman ini sehingga dapat merusak tanaman bahkan dapat membuat tanaman menjadi mati. (Welianto 2020).

Belalang merupakan salah satu hama yang menyerang tanaman hias yaitu pada tanaman parijoto, belalang muda maupun dewasa sangat rakus sehingga tanaman yang diserang hama ini memiliki gejala robekan pada daun, dan pada serangan yang parah hampir keseluruhan daun habis termasuk tulang daun (Bakoh, 2015). Sedangkan pada hama ulat yang menyerang tanaman parijoto ditandai dengan daun muda atau setengah tua yang rombeng dari pinggir. Gejala dari hama belalang dan ulat ini sama, yaitu daun menjadi rombeng. Hama belalang dapat ditanggulangi dengan penangkapan secara manual yaitu menangkap belalang yang belum bersayap atau saat masih pagi dan berembun biasanya belalang tidak dapat terbang dengan sayap basah (Ratih, 2012).

Penanggulangan pada hama ulat dapat dilakukan dengan mengambil ulat secara mekanis. Namun, bila jumlahnya sudah banyak, ulat dapat dibasmi dengan menyemprotkan insektisida 2 minggu sekali. Insektisida yang dapat digunakan adalah Decis 25 CE 0,5-1 ml/I, Atabron $1 \mathrm{ml} / \mathrm{I}$, atau Buldok 2,5 EC dosis 0,5-2 ml/I (Ratih, 2012).
Selain hama ada juga penyakit yang menyerangan tanaman ini yaitu serangan dari jamur Fussarium oxysporum adalah layu daun menguning mulai dari bagian bawah merambat ke atas dan akhirnya mengakibatkan kematian tanaman (Pusat Penelitian dan Pengembangan Hortikultura 2021). Dan tanaman hias pada bagian daun terdapat bercak berwarna kuning sampai coklat kemerahan dan bercak hitam merupakan salah satu gejala akibat jamur Corcospora sp. dan Pestalotia sp. (Dwidjoseputro, 1978).

Pada umumnya tanaman hias disebabkan penyakit jamur yaitu bagian daun atau pucuk daun tanaman terdapat titik abu-abu kecoklatan atau kehitaman (Hikmah et al., 2018). Bercak coklat atau kehitaman pada daun tua merupakan salah satu penyakit yang menyerang tanamanan hias yang disebabkan oleh Cercospora sp (Suhardi, 2007). Selain penyakit yang menyerang tanamana hias, ditemukan juga hama pada daun parijoto terdapat bekicot. Akibat hama ini, akan menyebabkan kerusakan pada daun yaitu daun menjadi berlubang dan terkoyak dengan bekas gigitan tidak rata atau bergerigi sehingga akan menghambat proses fotosintesis (Pracaya, 2003). Oleh karena itu nilai jual tanaman hias akan menurun jika terdapat daun menjadi sobek atau berlubang-lubang besar (Maryani, 2013).

Dari berbagai gejala serangan dari hama dan penyakit menunjukkan ciri yang mirip, sehingga sulit diketahui jenis serangan karena kurang nya pengetahauan dalam penanganan serangan hama dan penyakit pada tanaman parijoto. Dari masalah tersebut, maka dibutuhkan cara agar dapat menentukan jenis serangan penyakit dan hama yang menyerang tanaman parijoto berdasarkan gejala yang diberikan serta penanganannya. (Nonci et al., 2019).

Berdasarkan masalah tersebut dibutuhkan penelitian untuk mengetahui hama dan juga penyakit pada tanaman parijoto untuk memberi kemudahan dalam mencari informasi tentang penyakit atau hama yang menyerang tanaman parijoto bagi masyarakat budidaya tanaman hias di Nglurah dan para pecinta tanaman hias khususnya. Maka dari itu penelitian ini bertujuan untuk mengidentifikasi dan mengetahui informasi tentang hama dan penyakit serta gejala pada tanaman parijoto. Penelitian ini menggunakan metode Observasi langsung dan wawancara pada pengelola (Pak Gio, 58 tahun) budidaya tanaman 
parijoto di Nglurah Tawangmangu. Data yang dianalisis menggunakan deskriptif kualitatif.

\section{Bahan dan Metode}

\section{Tempat dan Waktu Penelitian}

Penelitian ini dilaksanakan di Green House budidaya tanaman hias, salah satunya tanaman parijoto di Kampung Wisata Sewu Kembang Nglurah Tawangmangu, dimulai dari bulan JuliSeptember 2021. Tujuan penelitian ini yaitu untuk mengidentifikasikan hama dan penyakit parijoto (Medinilla speciosa blume).

\section{Alat dan Bahan}

Sampel penelitian yang digunakan adalah tanaman parijoto (Medinilla speciosa blume. Alat yang digunakan berupa alat tulis, dan alat dokumentasi (kamera ponsel).

\section{Variabel Penelitian}

Variabel yang diamati dalam penelitian ini meliputi : Hama dan penyakit yang ada, serta gejala-gejala yang ditimbulkan pada tanaman parijoto (Medinilla speciosa blume).

\section{Metode dan analisis data}

Dari Permasalahan yang dialami oleh masyarakat budidaya tanaman hias dan pecinta tanaman hias parijoto (Medinilla speciosa blume), untuk menjawab permasalahan tersebut oleh karen itu menggunakan metode observasi secara langsung serta wawancara dengan pak Gio selaku pengelola budidaya tanaman parijoto di Nglurah Tawangmangu, data dianalisis secara deskriptif kualitatif.

\section{Tahapan Penelitian}

a. Mengamati tanaman parijoto yang tumbuh didaerah penelitian

b. Mengamati dan mengidentifikasikan hama dan penyakit apa saja yang muncul pada tanaman tersebut

c. Mencatat dan mendokumentasi apa yang ditemukan dilokasi penelitian tentang hama dan penyakit pada tanaman parijoto d. Menganalisis penyebab serta cara penanggulangan terhadap hama dan penyakit pada tanaman parijoto

e. Membuat laporan penelitian

\section{Hasil dan Pembahasan}

\section{Hasil pengamatan hama dan penyakit tanaman parijoto}

Penelitian ini dilakukan di Green House budidaya tanaman hias salah satunya tanaman parijoto di Kampung Wisata Sewu Kembang Nglurah Tawangmangu, dilaksanakan pada Sabtu, 04 September 2021. Pada penelitian ini mengunakan metode observasi secara langsung serta wawancara dengan pak Gio selaku pengelola budidaya tanaman parijoto di Nglurah Tawangmangu dan data dianalisis secara deskriptif kualitatif. Penelitian ini dilakukan untuk pengamatan dan identifikasi penyakit dan hama serta gejala-gejala pada tanaman parijoto dengan menggunakan 10 sampel tanaman parijoto (Medinilla speciosa blume).

\section{Deskripsi hasil penelitian}

Pada tabel hasil penelitian ditemukan serangan hama dan penyakit serta gejalanya sebagai berikut :

\section{Parijoto 1}

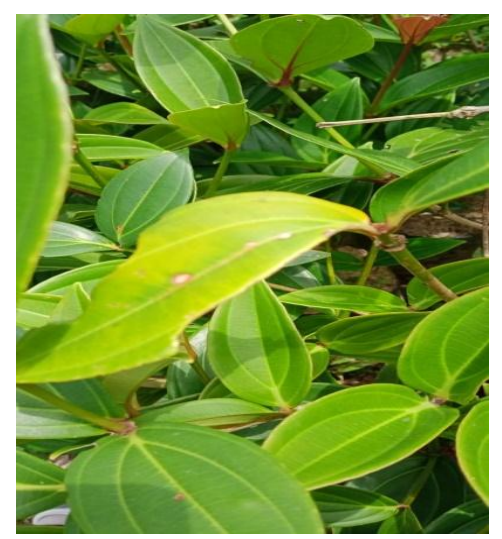

Gambar 1.2 parijoto (Dok. Pribadi)

Pada tanaman parijoto 1 terdapat jamur fussarium oxysporum ini menyerang tanaman parijoto pada bagian daun yang menyebabkan Daun layu dan berwarna kekuningan. 


\section{Parijoto 2}

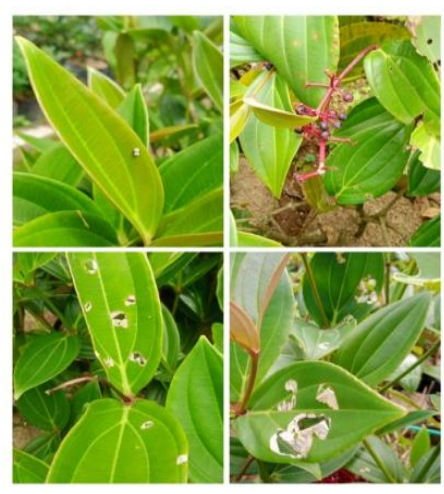

\section{Gambar 1.3 parijoto (Dok Pribadi)}

Pada tanaman parijoto 2 terdapat hama bekicot, hama bekicot ini menyerang tanaman parijoto pada bagian daun sehingga menyebabkan Daun berlubang, tepi daun rusak dengan bekas gigitan yang tidak rata atau bergerigi. Hasil pengamatan langsung di lapangan ditemukan bekicot yang masih kecil pada daun di atas permukaan daun parijoto.

\section{Parijoto3}

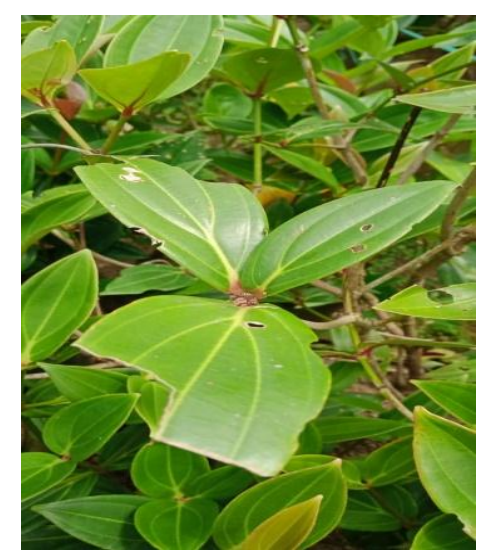

Gambar 1.4 parijoto (Dok. Pribadi)

Pada tanaman parijoto 3 terdapat hama ulat, hama ulat ini menyerang tanaman parijoto pada bagian daun sehingga akan menyebabkan Daun dengan bekas gigitan dari pucuk daun sampai berbentuk gerigi.

\section{Parijoto 4}

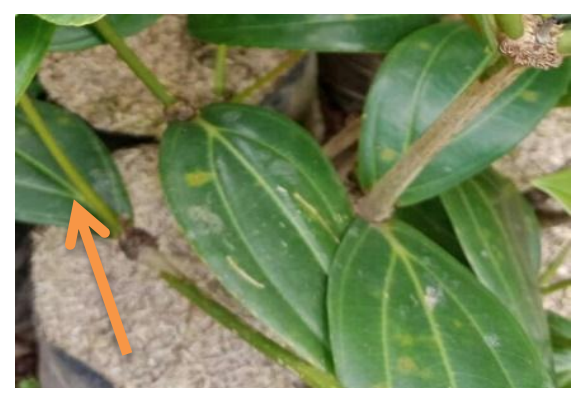

Gambar 1.5 parijoto (Dok. Pribadi)

Pada tanaman parijoto 4 terdapat jamur cercospora $\mathrm{sp}$ dan pestalotia sp yang menyerang tumbuhan parijoto pada bagian daun, menyebabkan bercak berwarna kuning.

\section{Parijoto 5}

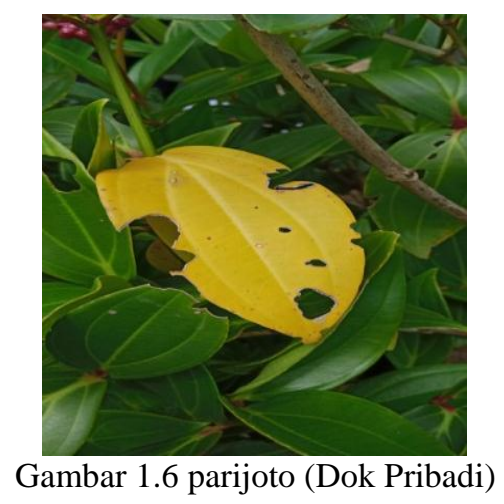

Pada tanaman parijoto 5 terdapat penyakit jamur Jamur fussarium oxysporum yang menyerang tumbuhan parijoto pada bagian daun, menyebabkan Daun berubah warna kuning dengan bercak coklat kemerahan.

\section{Parijoto 6}

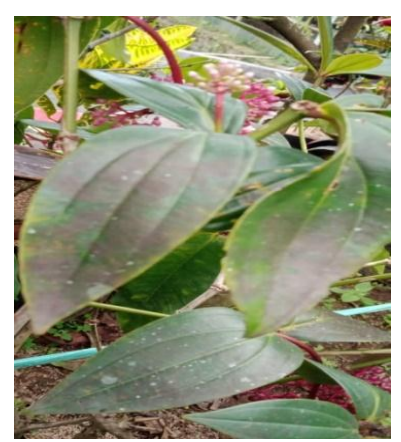

Gambar 1.7 parijoto (Dok Pribadi) 
Pada Pada tanaman parijoto 6 terdapat penyakit Jamur cercospora sp dan pestalotia sp yang menyerang tumbuhan parijoto pada bagian daun, menyebabkan Daun mengalami bercak merah kehitaman.

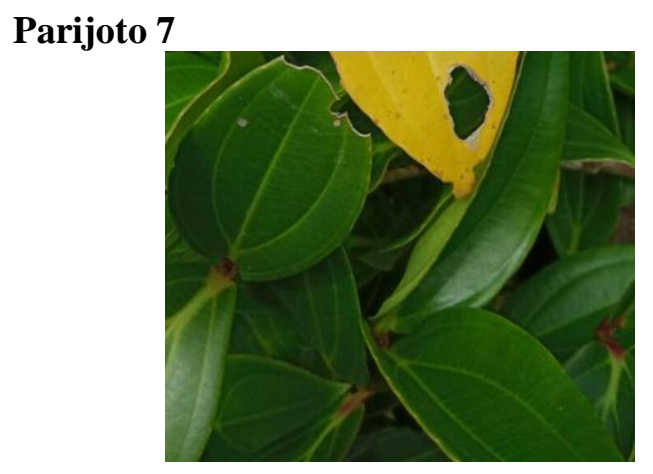

Gambar 1.8 parijoto (Dok Pribadi)

Pada tanaman parijoto 7 terdapat hama ulat, hama ulat ini menyerang tanaman parijoto pada bagian daun sehingga akan menyebabkan Daun mengalami bekas gigitan tidak merata/ bergerigi dari pinggir daun.

\section{Parijoto 8}

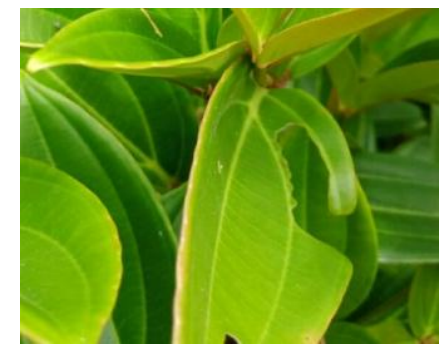

Gambar 1.9 parijoto (Dok Pribadi)

Pada tanaman 8 terdapat hama belalang, hama belalang ini menyerang tanaman parijoto pada bagiam daun sehingga akan mengakibatkan Daun menjadi rombeng.

\section{Parijoto 9}

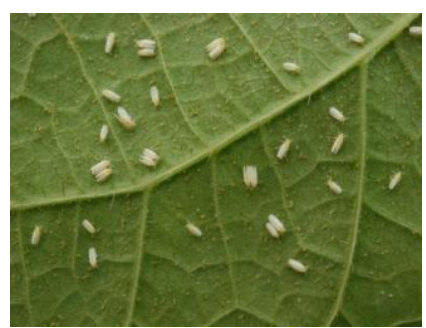

Gambar 1.10 Parijoto (Dok Pribadi)
Pada tanaman parijoto 8 terdapat hama kutu putih, hama kutu putih ini menyerang tanaman parijoto pada bagian ketiak daun sehingga Kutu putih menghisap cairan daun dan Meninggalkan jelaga pada daun yang akan menyebabkan daun lepas dan layu.

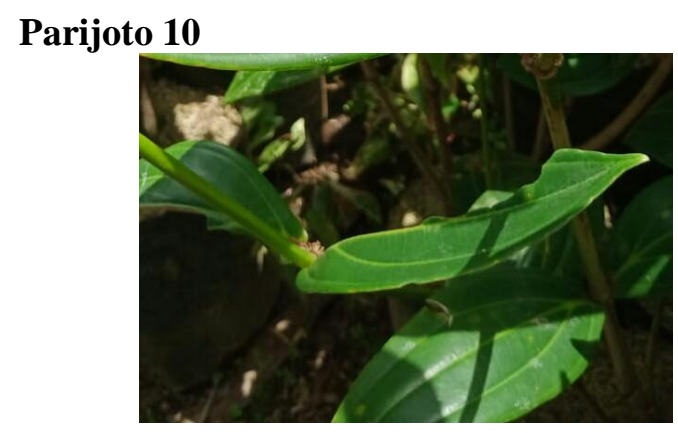

Gambar 1.11 parijoto (Dok Pribadi)

Pada tanaman 10 terdapat hama belalang, hama belalang ini menyerang tanaman parijoto pada bagian daun sehingga akan mengakibatkan Daun menjadi rombeng dengan bekas gigitan.

\section{Hama dan penyakit yang ditemukan pada tanaman parijoto}

Pada penelitian ini ditemukan 4 jenis hama dan 2 penyakit yang menyerang tanaman parijoto. Hama yang menyerang tanaman parijoto berupa bekicot, kutu putih, ulat, dan belalang sedangkan tanaman parijoto yang diserang oleh penyakit yaitu berupa jamur cercospora $s p$ dan pestalotia $s p$ dan jamur fussarium oxysporum. Hama keempat jenis tersebut dapat menyebabkan pertumbuhan tanaman parijoto kurang baik, daun menguning dan layu sehingga tanaman ini dapat mati hal ini sesuai dengan pernyataan Welianto (2020) bahwa Hama yang menyerang pada tanaman parijoto seperti kutu putih, belalang, bekicot, ulat, dan perubahan lingkungan membuat beberapa hama dapat menjadi predator bagi tanaman ini sehingga dapat merusak tanaman bahkan dapat membuat tanaman menjadi mati. Sedangkan penyakit yang menyerang tanaman parijoto seperti jamur Fussarium oxysporum akan menyebabkan tanaman parijoto mati sesuai pernyataan Pusat Penelitian dan Pengembangan Hortikultura (2021) dan juga tanaman hias pada bagian daun terdapat bercak berwarna kuning sampai coklat kemerahan dan bercak hitam merupakan salah satu gejala akibat 
jamur Corcospora sp. dan Pestalotia sp sesuai juga dengan pernyataan Dwidjoseputro (1976).

Untuk itu solusi perawatan tanaman parijoto agar terhindar dari hama dan penyakit membutuhkan perawatan yang ekstra seperti memperhatikan kelembaban tanah, pemberian pupuk yang sesuai, serta pemberian vitamin agar tanaman parijoto dapat tumbuh dengan baik,dan juga untuk perawatan tanaman parijoto lainya sesuai dengan pernyataan Muttaqin (2021). Dan penyiraman tanaman parijoto dilakukan 2 kali sehari dengan secukupnya. Untuk menanggulangi hama belalang dengan penangkapan secara manual yaitu menangkap belalang yang belum bersayap atau saat masih pagi dan berembun biasanya belalang tidak dapat terbang dengan sayap basah. Sedangkan Penanggulangan pada hama ulat dapat dilakukan dengan mengambil ulat secara mekanis. Namun, bila jumlahnya sudah banyak, ulat dapat dibasmi dengan menyemprotkan insektisida 2 minggu sekali. Insektisida yang dapat digunakan adalah Decis 25 CE 0,5-1 ml/I, Atabron $1 \mathrm{ml} / \mathrm{I}$, atau Buldok 2,5 EC dosis 0,5-2 ml/I sesuai dengan pernyataan Ratih (2012).

\section{Kesimpulan}

Dari hasil penelitian ini dapat disimpulkan bahwa terdapat hama dan penyakit pada 10 sampel diantaranya hama ulat, bekicot, belalang, kutu putih sedangkan untuk penyakit yaitu terdapat jamur Fussarium oxysporum, jamur Cercospora sp dan Pestalotia sp.

\section{Ucapan Terima Kasih}

Kami mengucapkan banyak terima kasih kepada Bapak dan Ibu Dosen Pembimbing Pendidikan Biologi Universitas Veteran Bangun Nusantara Sukoharjo yang telah memberikan ijin dalam penelitian ini, dan Pengelola budidaya tanaman hias di Nglurah Tawangmangu serta teman mahasiswa yang telah membantu pelaksanaan penelitian dari awal sampai akhir.

\section{References}

Bakoh, B. (2015). Serangan Belalang Kembara Di Kabupaten Bone, Sulawesi Selatan. http://Ditjenbun.pertanian.go.id
Dwidjoseputro, D. (1978). Pengantar Mikologi. Penerbit Alumni. Bandung.

Elfrida, Elsa (2015). Uji Efek Anthihiperlipidemia Ekstrak ETANOL 96\% Buah Parijoto (Medinilla Speciosa blume) Terhadap Jaringan hati tikus jantan.UIN Syarif Hidayatullah. Jakarta.

Fitri, Anisa (2019). "Pengaruh Ekstrak Terhadap Hama Kutu Putih." Universitas Islam Negeri Raden Intan. URL: http://repository.radenintan.ac.id/7288/1/Sk ripsi

Hidayati Rahmawati (2020). Formulasi Dan Uji Stabilitas Nanoemulsi Ekstrak Buah Parijoto (Medinilla Speciosa blume). Ngudi Waluyo University URL: http://repository2.unw.ac.id/586/

Imaniar Agustina Ratih (2012). Sistem Pakar Untuk Mendiagnosa Hama Penyakit Tanaman. Jurnal Ilmu komputer, 1(1), Oktober 2012

Islakhul Muttaqin (2021). Parijoto, Dari Mitos Menjadi Olahan Andalan Kudus

Jurus tani (2019). Budidaya Parijoto. URL:https://jurustani.com/budidayaparijoto

Kementerian Negara Riset dan Teknologi (2015). Medinilla speciosa. http://www.warintek.ristek.go.id. Diakses pada tanggal 09 September 2021

Mumpuni, K. E. (2014). Integrasi Potensi Dan Kearifan Lokal Sebagai Pengembangan Modul Materi Keanekaragaman Hayati Dan Konservasi. Tesis tidak dipublikasikan. Malang: PPS Universitas Negeri Malang

Musfirah, et al., (2016). Potensi Ekstrak Etanol 70\% Akar Saluang Balum (Lavanga Sarmentosa Blume Kurtz) Terhadap Kualitas Dan Viabilitas Sperma Mencit, Pharmaciana, 6 (2), 131-138. 
Nadhiroh, Fatma Rosiatin (2019). 5 Fakta Menarik Buah Parijoto, Tanaman Hias Sekaligus Obat Herbal. URL: https://www.idntimes.com/science/discover y/fatma-roisatin-nadhiroh/5-fakta-menarik$\underline{\text { buah-parijoto-c1c } 2 / 5}$

Niswah, lukluatun (2014). Uji Aktivitas Antibakteri Dari Ekstrak Buah Parijoto (Medinilla Speciosa Blume) Menggunakan Metode Difusi Cakram. URL: https://repository.uinjkt.ac.id/dspace/handle $\underline{/ 123456789 / 26130}$

Nonci, Nurnina et al. (2019). Badan Penelitian Dan Pengembangan Pertanian Balai Penelitian Tanaman Serealia PENGENALAN FALL ARMYWORM. 1st Ed. Maros: Balai Penelitian Tanaman Serealia.

URL: http://kaltim.litbang.pertanian.go.id/ind

Pracaya (2003). Hama Dan Penyakit Tanaman. Kanisius.Yogyakarta

Rimba kita (2019). Parijoto - Taksonomi, Morfologi, Asal, Habitat, Kandungan \& Manfaat Buah. URL: https://rimbakita.com/parijoto

Welianto, Ari. (2020). "Hama Dan Penyakit Pada Tumbuhan." https:// hama-dan-penyakitpada-tumbuhan-arti-jenis-dan-contohnya.

Widi, Muryono (2014). Napak Jejak Pemikiran Sunan Muria, (Kudus: LPS Fikro, 2014), hal.30-33
Widjanarko, M. (2013). Jelajah Muria. Muria Research Center, Kudus. Halaman 2.

Zuhud, E. A.M., Sinroyo, Sandra, E., Hikmat, A., \& Adhiyanto, E. (2014). Buku Acuan Umum Tumbuhan Obat Indonesia Jilid VI. Dian Rakyat, Jakarta

Hikmah, N., Amelia, C. R., \& Ariani, D. (2018). Pengaruh Pemberian Masase Effleurage Menggunakan Minyak Aromaterapi Mawar terhadap Penurunan Intensitas Nyeri Dismenore pada Remaja Putri di SMK Negeri 2 Malang. https://doi.org/10.37676/jnph.v6i2.650

Suhardi, S. (2007). Efektivitas Fungisida Untuk Pengendalian Penyakit Berdasarkan Curah Hujan Pada Mawar. Jurnal Hortikultura. https://doi.org/10.21082/jhort.v17n4.2007.p

Maryani, P. Astuti., \& M. Napitupulu (2013). Pengaruh Pemberian Pupuk Organik Cair Nasa Dan Asal Bahan Tanam Terhadap Pertumbuhan Dan Hasil Tanaman Stroberi (Fragaria sp). Jurnal Agrifor, XII (2), 160-175. Oktober 2013.

Suhada, S. (2014). Sistem pakar pengidentifikasi hama pada tanaman Anggrek terestrial berbasis mobile. (1), 37-43.

Hafidh, F. (2017). Penerapan metode Iterative Dichotomizer (ID3) untuk diagnosa hama tanaman Anggrek. 39-42. 